\title{
Service Gaps of a Banking System: A Case Study on Basic Bank
}

\author{
Md. Shariful Islam ${ }^{1}$, Md. Mahmud $\operatorname{Hasan}^{2} \&$ Mohammad Al-Amin Khan ${ }^{3}$ \\ ${ }^{1}$ BBA, MBA, Department of Marketing, Jahangirnagar University, Savar, Dhaka, Bangladesh \\ ${ }^{2}$ Lecturer, Department of Accounting, Dhaka Commerce College, Mirpur, Dhaka, Bangladesh \\ ${ }^{3}$ BBA, Department of Finance \& Banking, Jahangirnagar University, Savar, Dhaka; MBA (IBA), University of \\ Dhaka, Bangladesh \\ Correspondence: Md. Shariful Islam; BBA, MBA, Department of Marketing, Jahangirnagar University, Savar, \\ Dhaka 1342, Bangladesh. E-mail: sharifjumkt39@gmail.com
}

$\begin{array}{lc}\text { Received: August 17, } 2015 \quad \text { Accepted: September 1, } 2015 \quad \text { Online Published: September 29, } 2015 \\ \text { doi:10.5539/ijms.v7n5p107 } & \text { URL: http://dx.doi.org/10.5539/ijms.v7n5p107 }\end{array}$

\begin{abstract}
Financial liberalization has led to intense competitive pressures and private banks dealing in retail banking are consequently directing their strategies towards increasing service quality level which fosters customer satisfaction and loyalty through improved service quality. This article examines the influence of perceived service quality on customer satisfaction. In this paper, we have used SERVQUAL as a technique to measure service quality and identify gaps in a BASIC Bank. The results of this study showed that there are service quality gaps between customers' expectations and their perceptions in six dimensions. In this issue paying attention to the effective factors on customers' expectations and its relationship with services quality is one of the important issues of the evaluation of services quality. For this purpose, the recent research was performed based on gap analysis model with the purpose of investigating the quality of banking services on the level of BASIC Bank. It was concluded after determining the desirable services from the standpoints of the customers (investigating customers' expectations) and its effective factors and also the examination of the current status of services quality (customers' understandings) that BASIC Bank responses to customers' expectations in all of the branches under investigation and the understood services quality has been always more than services quality expected by the customers.
\end{abstract}

Keywords: service gap, service quality, SERVQUAL model, service quality gap, perceived service

\section{Introduction}

The economy of a country is largely dependent on banking sector. In this case, Bangladesh is not exceptional. BASIC Bank is playing a great role to develop the economy of Bangladesh. Client expectations are increasing day by day from this bank. That is why; managers in BASIC Bank are under increasing pressure to demonstrate that their services are customer-focused and that continuous performance improvement is being delivered. In spite of having resource constraints, the banks must concentrate whether the customer expectations are properly understood and measured. They will also focus on whether any gaps from client point of view are identified. This information then assists a manager in identifying cost-effective ways of closing service quality gaps and of prioritizing which gaps to focus on - a critical decision given scarce resources. One of the aims of this study involves the use of service gap model in order to ascertain any actual or perceived gaps between customer expectations and perceptions of the service offered. Another aim of this paper is to point out how management of these banks can close these gaps effectively.

\section{Literature Review}

Services can be characterized as any process or good that one organization offers to other that is essentially impalpable and does not ensue in ownership of anything. Its creation may or may not be equal to a animal fluid. A band's offerings often let whatever services (Lovelock Christopher, 2004). The nature of most services is such that the customer is present in the delivery process. This means that the perception of quality is influenced not only by the 'service outcome' but also by the 'service process' (Ghobadian et al., 1994).

Many researchers and authors define service qualities in different ways. Service quality is defined as how well the service meets or exceeds the customers' expectations on a consistent basis (Crosby, 1979; Parasuraman et al., 
1985). Parasuraman et al., Liljander, and Tore agreed that service quality is the difference between expectation and the performance of the service or the perception of the customer. Liljander and Tore (1992) defined service quality as "the difference between what a service company should offer and what it actually does offer." In some earlier studies, service quality has been referred as the extent to which a service meets customers' needs or expectations (Lewis \& Mitchell, 1990; Dotchin \& Oakland, 1994).

Service quality is so important that companies have gone to great efforts to evaluate and keep records of service quality levels (Hauser \& Clausing, 1988; Phillips et al., 1983; Zeithaml et al., 1990). Many industries are paying greater attention to service quality and customer satisfaction, for reasons such as increased competition and deregulation (Reichheld \& Sasser, 1990; Schlesinger \& Heskett, 1991). The academic literature proposes that customer satisfaction is a function of the discrepancy between a consumer's prior expectation and his or her perception regarding the purchase (Churchill \& Surprenant, 1982; Oliver, 1977). As reported in the relevant literature high quality service helps to generate customer satisfaction, customer loyalty, and growth of market share by soliciting new customers, and improved productivity and financial performance (Lewis, 1993; Andereson et al., 1994).

Parasuraman and his colleagues developed the service quality measurement model known as SERVQUAL. This model is based on a comparison between the customer's expectations of the standard of service he/she will receive and his/her perception of the standard of service that is actually delivered. Furthermore, Parasuraman et al. see their service quality measurement model as one of the models that have been shown to enjoy a high degree of validity and stability. The model attempts to show the salient activities of the service organization that influence the perception of quality. Moreover, the model shows the interaction between these activities and identifies the linkages between the key activities of the service organization or marketer, which are pertinent to the delivery of a satisfactory level of service quality. The links are described as gaps or discrepancies: that is to say, a gap represents a significant hurdle to achieving a satisfactory level of service quality (Ghobadian et al., 1994).

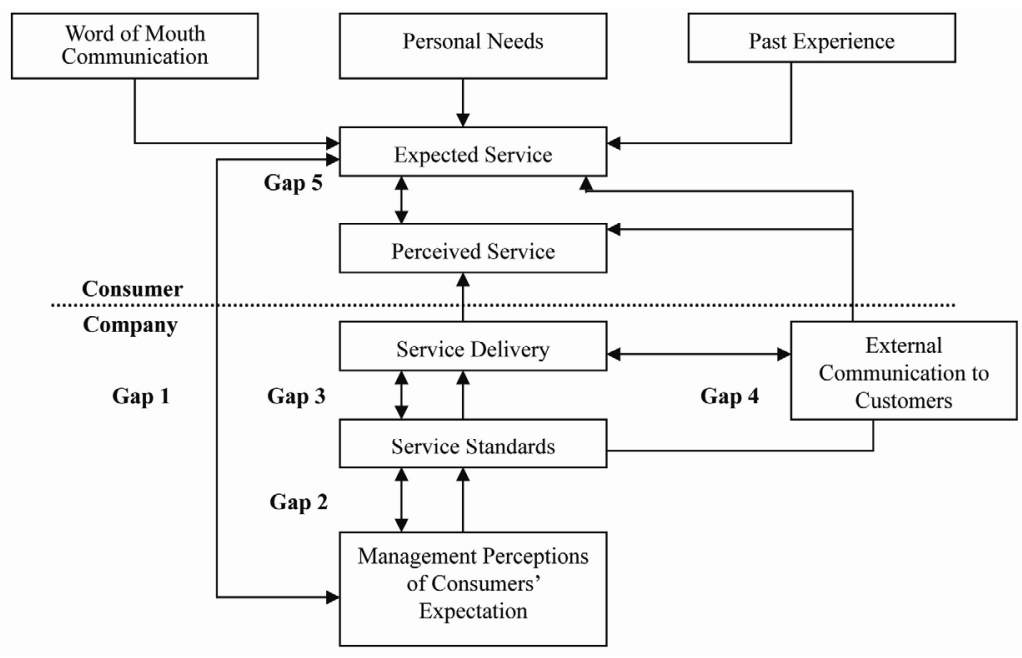

Figure 1. Conceptual model of service quality gap

Source: Parasuraman, A., Zeithaml, V., \& Berry, L. L. (1985, 1998).

The upper part of the model (Figure 1) includes phenomena tied to the consumer, while the lower part shows phenomena tied to the supplier of services. The primary thesis of this model is that the service quality shortfall (i.e., Gap 5, the gap between customer service expectations and perceptions) is the result of a series of shortfalls within the service provider's organization (i.e., Gaps 1-4). Thus, improving the quality of service experienced by customers (i.e., closing Gap 5) requires diagnosing the causes of and correcting the internal deficiencies (i.e., Gaps 1-4) (Parasuraman et al., 2004).

Luk and Layton (2002) developed the traditional model of Parasuraman et al. (1998) by adding two more gaps. They reflect the differences in the understanding of consumer expectations by manager and front-line service providers and the differences in consumer expectations and service providers' perception of such expectations. This model is illustrated in Figure 2. 


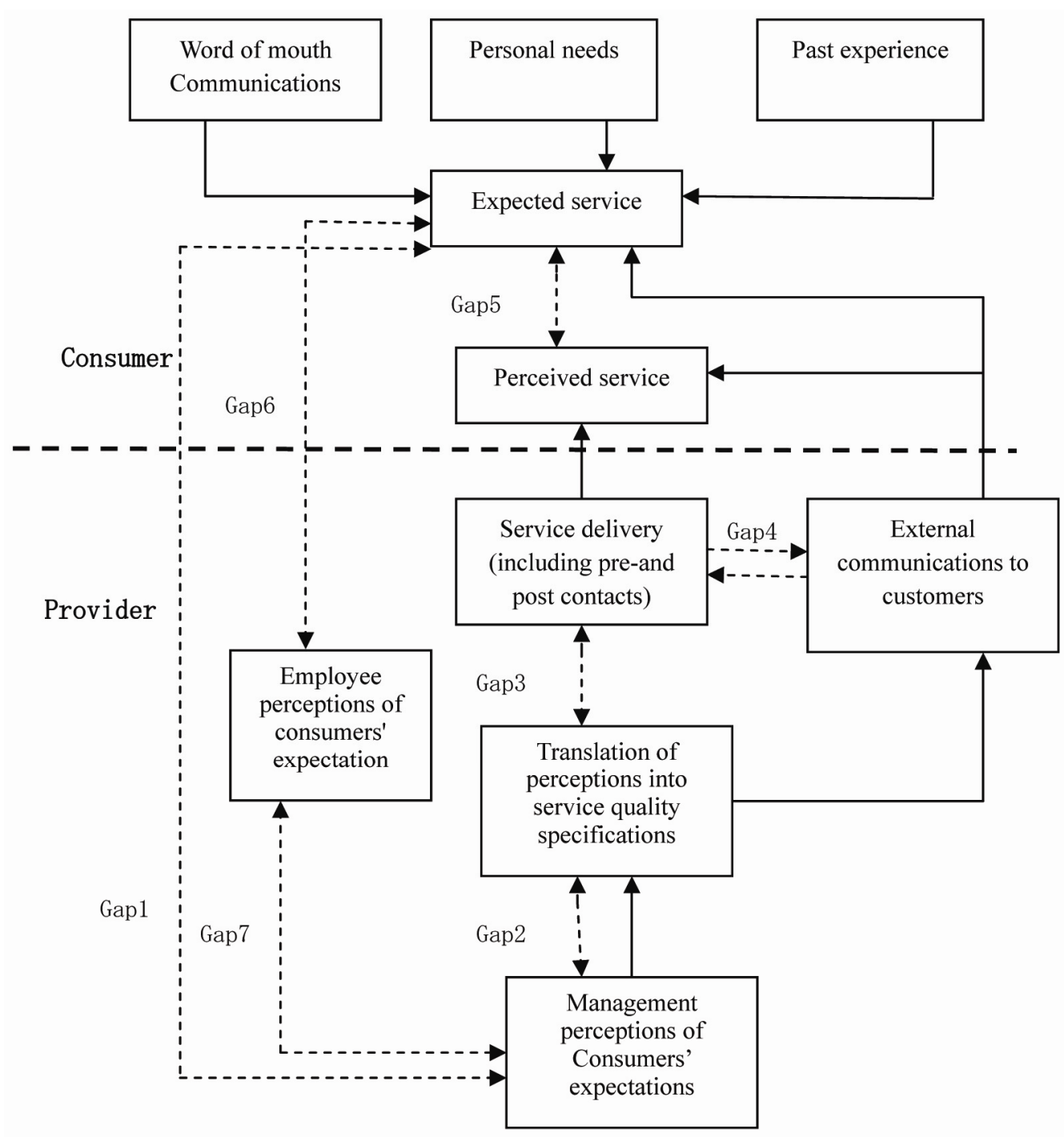

Figure 2. Conceptual model of service quality gap

Source: Parasuraman et al., 1985; Curry, 1999; Luk and Layton, 2002.

These seven gaps are described below briefly.

GAP 1: Customers' expectations versus management perceptions: This gap occurs because of the lack of a marketing research orientation, inadequate upward communication and too many layers of management.

GAP 2: Management perceptions versus service specifications: It happens because of inadequate commitment to service quality, a perception of unfeasibility, inadequate task standardization and an absence of goal setting.

GAP 3: Service specifications versus service delivery: The third gap takes place because of role ambiguity and conflict, poor employee-job fit and poor technology-job fit, inappropriate supervisory control systems, lack of perceived control and lack of teamwork.

GAP 4: Service delivery versus external communication: It arises from inadequate horizontal communication and propensity to over-promise.

GAP 5: The discrepancy between customers' expectations and their perceptions of the service delivered: Because of the influences exerted from the customer side and the shortfalls (gaps) on the part of the service provider, the fifth gap that is known as customer gap, happens.

GAP 6: The discrepancy between customers' expectations and employees' perceptions: This gap is created because of the differences in the understanding of customers' expectations by front-line service providers. 
Gap7: The discrepancy between employee's perceptions and management perceptions: The seventh gap happens because of the differences in the understanding of customers' expectations between managers and service providers.

According to Brown and Bond (1995), "the gap model is one of the best received and most valuable contributions to the services literature". The model identifies seven key discrepancies or gaps relating to managerial perceptions of service quality, and tasks associated with service delivery to customers. The first six gaps (Gap 1, Gap 2, Gap 3, Gap 4, Gap 6, and Gap 7) are identified as functions of the way service is delivered, whereas Gap 5 pertains to the customer and as such is considered to be the true measure of service quality.

\section{Objectives of the Study}

The main objective of the study is to measure Service Gap of BASIC Bank with SERVQUAL Model. Besides there are some other major objectives:

- To find the most important dimension of service quality that affect customer satisfaction.

- To measure the satisfaction level of current customers of this bank.

- To recommend some guidelines to ensure quality services.

\section{Research Question and Hypothesis Development}

The entire report tried to find out whether there is any service gap that customers feel while taking service from BASIC Bank. Thus, this report has focused on following research question.

\section{RQ: Is there any gap between expected service and perceived service by the account holders of BASIC bank?}

To find out the answer to the research question as well as to test whether the response is logical, following hypotheses have been developed.

$H_{o}$ : There is a gap between the expected and perceived service

$H_{1}$ : There is no gap between the expected and perceived service

\section{Methodology}

\subsection{Type of Research and Data Sources}

'Descriptive Research' has been conducted to measure the extent of the problem. 'Paired Sample t-test' has been used here to show how the provider gaps affect the customer gap. This study covered two types of data, which are: Primary data (Survey method, Personal observation) and Secondary data (Web information, Journals, Published reports on service quality of BASIC Bank etc.).

\subsection{Sampling and Sample Size}

Stratified Sampling Technique has been used to collect data. The entire sampling frame is divided into four strata: Student, Service Holders, Business People and Professionals. From each stratum, 32, 20, 20, and 28 respondents are selected respectively. Here data has been collected from respondents through personal interviews and e-mail.

\subsection{Questionnaire Development}

A structured questionnaire has been used here to collect data. The questionnaire has been developed in a way that reveals the respondent's response related to each of the independent variables. The questionnaire has been formed on 5-points Likert Scale to measure the degree of perception of respondents on each variable. The respondents were asked to rate statements based on their perception; from 1 to 5 where 1 signifies Strong Disagreement and 5 indicates Strong Agreement.

\subsection{Statistical Analytics and Tools}

The study has been conducted based on two groups. The first group entails the expected services by the account holders of BASIC bank. On the other hand, the second group explains the perceived services of those account holders. As there are two groups in the analysis and it is required to find out the gap among their responses about the service quality of BASIC bank, Paired Sample t-test has been conducted for Two Samples. Before testing the hypothesis, an apparent view has been given on the mean values of the responses to validate the findings. Statistical package SPSS 16.0 has been used to analyze the data.

\subsection{Paired t-Test for Two Samples: At a Glance}

A $t$-test is any statistical hypothesis test in which the test statistic follows a Student's $t$ distribution if the null hypothesis is supported. It can be used to determine if two sets of data are significantly different from each other, and is most commonly applied when the test statistic would follow a normal distribution if the value of a scaling 
term in the test statistic were known. A paired sample t-test is used to determine whether there is a significant difference between the average values of the same measurement made fewer than two different conditions. Both measurements are made on each unit in a sample, and the test is based on the paired differences between these two values. The usual null hypothesis is that the difference in the mean values is zero. In statistics, a paired difference test is a type of location test that is used when comparing two sets of measurements to assess whether their population means differ. A paired difference test uses additional information about the sample that is not present in an ordinary unpaired testing situation, either to increase the statistical power, or to reduce the effects of confounders.

\section{Analysis and Findings}

Since the first purpose of this study is to measure the provider gaps, it is necessary to track the difference among the responses based on the services customers expect and what they actually perceive. In doing so, the means and the standard deviations of the responses have been compared.

Table 1. Paired Samples Statistics

\begin{tabular}{|c|c|c|c|c|c|}
\hline & & Mean & $\mathbf{N}$ & Std. Dev. & Std. Error Mean \\
\hline \multirow[t]{2}{*}{ Pair 1} & Q1a_expected_service_match_with_BASIC_Bank & 3.82 & 100 & .687 & .069 \\
\hline & Q1b_perceived_service_match_with_BASIC_Bank & 3.75 & 100 & .716 & .072 \\
\hline \multirow[t]{2}{*}{ Pair 2} & Q2a_expected_management_emphasizes_on_customer_relationship & 4.07 & 99 & .918 & .092 \\
\hline & Q2b_perceived_management_emphasizes_on_customer_relationship & 3.55 & 99 & .918 & .092 \\
\hline \multirow[t]{2}{*}{ Pair 3} & Q3a_expected_managers_know_customer_expectation & 3.93 & 99 & 1.003 & .101 \\
\hline & Q3b_perceived_managers_know_customer_expectation & 3.37 & 99 & .876 & .088 \\
\hline \multirow[t]{2}{*}{ Pair 4} & Q4a_expected_physical_facilities_visually_appealing & 3.79 & 98 & .790 & .080 \\
\hline & Q4b_perceived_physical_facilities_visually_appealing & 3.50 & 98 & .933 & .094 \\
\hline \multirow[t]{2}{*}{ Pair 5} & Q5a_expected_quality_standard_reflect_customer_expectation & 3.95 & 99 & .919 & .092 \\
\hline & Q5b_perceived_quality_standard_reflect_customer_expectation & 3.55 & 99 & .860 & .086 \\
\hline \multirow[t]{2}{*}{ Pair 6} & Q6a_expected_customer_driven_standard & 3.90 & 97 & .930 & .094 \\
\hline & Q6b_perceived_customer_driven_standard & 3.59 & 97 & 688 & .070 \\
\hline \multirow[t]{2}{*}{ Pair 7} & Q7a_expected_employee_skill_to_provide_service & 3.91 & 98 & .886 & .090 \\
\hline & Q7b_perceived_employee_skill_to_provide_service & 3.54 & 98 & .839 & .085 \\
\hline \multirow[t]{2}{*}{ Pair 8} & Q8a_expected_employee_eagerness_to_learn_things & 4.09 & 97 & .843 & .086 \\
\hline & Q8b_perceived_employee_eagerness_to_learn_things & 3.37 & 97 & .905 & .092 \\
\hline \multirow[t]{2}{*}{ Pair 9} & Q9a_expected_ads_reflect_services & 3.85 & 98 & .866 & .087 \\
\hline & Q9b_perceived_ads_reflect_services & 3.35 & 98 & .909 & .092 \\
\hline \multirow[t]{2}{*}{ Pair 10} & Q10a_expected_communication_to_educate_customer & 3.91 & 98 & .898 & .091 \\
\hline & Q10b_perceived_communication_to_educate_customer & 3.34 & 98 & .952 & .096 \\
\hline \multirow[t]{2}{*}{ Pair 11} & Q11a_expected_employee_enquiry_customer_expectation & 4.11 & 93 & .787 & .082 \\
\hline & Q11b_perceived_employee_enquiry_customer_expectation & 3.45 & 93 & .854 & .089 \\
\hline \multirow[t]{2}{*}{ Pair 12} & Q12a_expected_individual_attention_to_customer & 4.13 & 99 & .723 & .073 \\
\hline & Q12b_perceived_individual_attention_to_customer & 3.48 & 99 & .952 & .096 \\
\hline \multirow[t]{2}{*}{ Pair 13} & Q13a_expected_bank_improve_services & 4.09 & 98 & .774 & .078 \\
\hline & Q13b_perceived_bank_improve_services & 3.53 & 98 & .802 & .081 \\
\hline \multirow[t]{2}{*}{ Pair 14} & Q14a_expected_less_bureaucratic_response & 4.02 & 100 & .710 & .071 \\
\hline & Q14b_perceived_less_bureaucratic_response & 3.44 & 100 & .729 & .073 \\
\hline
\end{tabular}

The average (mean) values of each sub-variable under the independent variables (provider gaps) have been calculated and then the mean of expected service and perceived service is defined. The test value of t-statistic is 3 indicating Neutral response. Any value over 3 indicates favorable response whereas any value below 3 denotes dissatisfactory responses. It has been assumed that the closer the mean values of expected and perceived service, the greater will be the customer satisfaction and the lower will be the service gap.

Pair 1: The pair between customers' expected service matching with customers' perceived service shows that the mean values are very close, 3.82 and 3.75 , respectively. Both the means fall in the satisfactory zone and are very close that indicates that there is less gap between what customers' expected and what they actually perceived. The value of standard deviation is also favorable that lower case of deviation falls in favorable zone for both the statements.

Pair 2: The pair between customers' expected service are matching with customers' perceived service shows that the mean values are not very close, 4.07 and 3.55, respectively. Though both the means fall in the 
satisfactory zone and are not too close which indicates that there is a gap between what customers' expected and what they actually perceived. At the lower case of standard deviation, still the gap between expectation and perception sustain.

Pair 3: The pair between customers' expected service are matching with customers' perceived service shows that the mean values are not very close, 3.55 and 3.93, respectively. Though both the means fall in the satisfactory zone and are not too close which indicates that there is a gap between what customers' expected and what they actually perceived. At the lower case of standard deviation, still the gap between expectation and perception sustain.

Pair 4: The pair between customers' expected service matching with customers' perceived service shows that the mean values are very close, 3.79 and 3.50, respectively. Both the means fall in the satisfactory zone and are very close that indicates that there is less gap between what customers' expected and what they actually perceived. The value of standard deviation is also favorable that lower case of deviation falls in favorable zone for both the statements.

Pair 5: The pair between customers' expected service matching with customers' perceived service shows that the mean values are very close, 3.95 and 3.55 , respectively. Both the means fall in the satisfactory zone and are very close that indicates that there is less gap between what customers' expected and what they actually perceived. The value of standard deviation is also favorable that lower case of deviation falls in favorable zone for both the statements.

Pair 6: The pair between customers' expected service matching with customers' perceived service shows that the mean values are very close, 3.90 and 3.59, respectively. Both the means fall in the satisfactory zone and are very close that indicates that there is less gap between what customers' expected and what they actually perceived. The value of standard deviation is also favorable that lower case of deviation falls in favorable zone for both the statements.

Pair 7: The pair between customers' expected service matching with customers' perceived service shows that the mean values are very close, 3.91 and 3.54, respectively. Both the means fall in the satisfactory zone and are very close that indicates that there is less gap between what customers' expected and what they actually perceived. The value of standard deviation is also favorable that lower case of deviation falls in favorable zone for both the statements.

Pair 8: The pair between customers' expected service are matching with customers' perceived service shows that the mean values are not very close, 4.09 and 3.37, respectively. Though both the means fall in the satisfactory zone and are not too close which indicates that there is a gap between what customers' expected and what they actually perceived. At the lower case of standard deviation, still the gap between expectation and perception sustain.

Pair 9: The pair between customers' expected service matching with customers' perceived service shows that the mean values are very close, 3.85 and 3.35 , respectively. Both the means fall in the satisfactory zone and are very close that indicates that there is less gap between what customers' expected and what they actually perceived. The value of standard deviation is also favorable that lower case of deviation falls in favorable zone for both the statements.

Pair10: The pair between customers' expected service are matching with customers' perceived service shows that the mean values are not very close, 3.91 and 3.34, respectively. Though both the means fall in the satisfactory zone and are not too close which indicates that there is a gap between what customers' expected and what they actually perceived. At the lower case of standard deviation, still the gap between expectation and perception sustain.

Pair11: The pair between customers' expected service are matching with customers' perceived service shows that the mean values are not very close, 4.11 and 3.45, respectively. Though both the means fall in the satisfactory zone and are not too close which indicates that there is a gap between what customers' expected and what they actually perceived. At the lower case of standard deviation, still the gap between expectation and perception sustain.

Pair12: The pair between customers' expected service are matching with customers' perceived service shows that the mean values are not very close, 4.13 and 3.48, respectively. Though both the means fall in the satisfactory zone and are not too close which indicates that there is a gap between what customers' expected and what they actually perceived. At the lower case of standard deviation, still the gap between expectation and perception sustain. 
Pair13: The pair between customers' expected service are matching with customers' perceived service shows that the mean values are not very close, 4.09 and 3.53, respectively. Though both the means fall in the satisfactory zone and are not too close which indicates that there is a gap between what customers' expected and what they actually perceived. At the lower case of standard deviation, still the gap between expectation and perception sustain.

Pair14: The pair between customers' expected service are matching with customers' perceived service shows that the mean values are not very close, 4.02 and 3.44, respectively. Though both the means fall in the satisfactory zone and are not too close which indicates that there is a gap between what customers' expected and what they actually perceived. At the lower case of standard deviation, still the gap between expectation and perception sustain.

Table 2. Paired Samples Test

\begin{tabular}{|c|c|c|c|c|c|c|c|c|c|}
\hline & & \multicolumn{5}{|c|}{ Paired Differences } & \multirow[t]{3}{*}{$\mathrm{t}$} & \multirow[t]{3}{*}{ df } & \multirow[t]{3}{*}{ Sig. } \\
\hline & & \multirow[t]{2}{*}{ Mean } & \multirow[t]{2}{*}{ Std. Dev. } & \multirow[t]{2}{*}{ Std. Error Mean } & \multicolumn{2}{|c|}{$\begin{array}{l}95 \% \text { CI of the } \\
\text { Difference }\end{array}$} & & & \\
\hline & & & & & Lower & Upper & & & \\
\hline Pair 1 & $\begin{array}{l}\text { Q1a_expected_service_match_with_ } \\
\text { BASIC_Bank } \\
\text { Q1b_perceived_service_match_with_ } \\
\text { BASIC_Bank }\end{array}$ & .070 & .590 & .059 & -.047 & .187 & 1.186 & 99 & .239 \\
\hline Pair 2 & $\begin{array}{l}\text { Q2a_expected_management_ } \\
\text { emphasizes_on_customer_relationship } \\
\text { Q2b_perceived_management_- } \\
\text { emphasizes_on_customer_relationship }\end{array}$ & .525 & .919 & .092 & .342 & .708 & 5.690 & 98 & .000 \\
\hline Pair 3 & $\begin{array}{l}\text { Q3a_expected_managers_know_ } \\
\text { customer_expectation } \\
\text { Q3b_perceived_managers_know_ } \\
\text { customer_expectation }\end{array}$ & .556 & 1.002 & .101 & .356 & .755 & 5.515 & 98 & .000 \\
\hline Pair 4 & $\begin{array}{l}\text { Q4a_expected_physical_facilities_ } \\
\text { visually_appealing } \\
\text { Q4b_perceived_physical_facilities_ } \\
\text { visually_appealing }\end{array}$ & .286 & .952 & .096 & .095 & .477 & 2.970 & 97 & .004 \\
\hline Pair 5 & $\begin{array}{l}\text { Q5a_expected_quality_standard_ } \\
\text { reflect_customer_expectation } \\
\text { Q5b_perceived_quality_standard__ } \\
\text { reflect_customer_expectation }\end{array}$ & .404 & .936 & .094 & .217 & .591 & 4.296 & 98 & .000 \\
\hline Pair 6 & $\begin{array}{l}\text { Q6a_expected_customer_driven_ } \\
\text { standard } \\
\text { Q6b_perceived_customer_driven__ } \\
\text { standard }\end{array}$ & .309 & .928 & .094 & .122 & .496 & 3.281 & 96 & .001 \\
\hline Pair 7 & $\begin{array}{l}\text { Q7a_expected_employee_skill_to_ } \\
\text { provide_service } \\
\text { Q7b_perceived_employee_skill_to_ } \\
\text { provide_service }\end{array}$ & .367 & .988 & .100 & .169 & .566 & 3.679 & 97 & .000 \\
\hline Pair 8 & $\begin{array}{l}\text { Q8a_expected_employee_eagerness_ } \\
\text { to_learn_new_things } \\
\text { Q8b_perceived_employee_eagerness_ } \\
\text { to_learn_new_things }\end{array}$ & .722 & 1.134 & .115 & .493 & .950 & 6.267 & 96 & .000 \\
\hline Pair 9 & $\begin{array}{l}\text { Q9a_expected_ads_reflect_service } \\
\text { Q9b_perceived_ads_reflect_service }\end{array}$ & .500 & 1.096 & .111 & .280 & .720 & 4.517 & 97 & .000 \\
\hline Pair 10 & $\begin{array}{l}\text { Q10a_expected_communication_to_ } \\
\text { educate_customers } \\
\text { Q10b_perceived_communication_to_- } \\
\text { educate_customer }\end{array}$ & .571 & .931 & .094 & .385 & .758 & 6.079 & 97 & .000 \\
\hline Pair 11 & $\begin{array}{l}\text { Q11a_expected_employee_enquiry_ } \\
\text { about_customer_expectation } \\
\text { Q11b_perceived_employee_enquiry_ } \\
\text { about_customer_expectation }\end{array}$ & .656 & 1.027 & .106 & .444 & .867 & 6.161 & 92 & .000 \\
\hline
\end{tabular}




\begin{tabular}{|c|c|c|c|c|c|c|c|c|c|}
\hline Pair 12 & $\begin{array}{l}\text { Q12a_expected_individual_attention_ } \\
\text { to_customer } \\
\text { Q12b_perceived_individual_attention_ } \\
\text { to_customer }\end{array}$ & .646 & 1.119 & .112 & .423 & .870 & 5.750 & 98 & .000 \\
\hline Pair 13 & $\begin{array}{l}\text { Q13a_expected_bank_improve_ } \\
\text { services } \\
\text { Q13b_perceived_bank_improve_ } \\
\text { services }\end{array}$ & .561 & .850 & .086 & .391 & .732 & 6.534 & 97 & .000 \\
\hline Pair 14 & $\begin{array}{l}\text { Q14a_expected_less_bureaucratic_ } \\
\text { response } \\
\text { Q14b_perceived_less_bureaucratic_ } \\
\text { response }\end{array}$ & .580 & .945 & .094 & .393 & .767 & 6.139 & 99 & .000 \\
\hline
\end{tabular}

Paired t-test has been used to test the hypotheses that there is a gap between expected and perceived services for all the 14 pairs.

\section{For Pair 1:}

\section{Step 1:}

H0: There is a gap between expected customer service and perceived customer service

H1: There is no gap between expected customer service and perceived customer service

Step 2: Level of Significance is considered at 0.05 level. The table value for t-distribution under corresponding degrees of freedom is 1.9842 .

Step 3: The decision rule is, if $\mathrm{t}_{\text {cal }}>\mathrm{t}_{\text {cri }}$, $\mathrm{H} 0$ will be rejected or if the significance value for a variable is less than 0.05 , the null hypothesis will be rejected.

Step 4: Here, the calculated value 1.186 is not greater than the table value and thus, null hypothesis cannot be rejected. Even, the significance value is 0.239 which is more than 0.05 , it ascertains that the null hypothesis is not rejected.

Step 5: Thus, it can be said that there is a gap between expected and perceived customer service of BASIC Bank. It denotes that there is still a way of improvement to satisfy customers.

\section{For Pair 2:}

\section{Step 1:}

H0: There is a gap between expected customer service and perceived customer service

H1: There is no gap between expected customer service and perceived customer service

Step 2: Level of Significance is considered at 0.05 level. The table value for t-distribution under corresponding degrees of freedom is 1.9842 .

Step 3: The decision rule is, if $t_{\text {cal }}>t_{\text {cri }}$, $H 0$ will be rejected or if the significance value for a variable is less than 0.05 , the null hypothesis will be rejected.

Step 4: Here, the calculated value 1.186 is greater than the table value and thus, null hypothesis can be rejected. As the significance value is 0.000 which is less than 0.05 , it ascertains that the null hypothesis can be rejected.

Step 5: Thus, it can be said that there is no gap or very little gap between expected and perceived customer service of BASIC Bank.

\section{For Pair 3:}

\section{Step 1:}

H0: There is a gap between expected customer service and perceived customer service

H1: There is no gap between expected customer service and perceived customer service

Step 2: Level of Significance is considered at 0.05 level. The table value for t-distribution under corresponding degrees of freedom is 1.9842 .

Step 3: The decision rule is, if $\mathrm{t}_{\text {cal }}>\mathrm{t}_{\text {cri }}, \mathrm{H} 0$ will be rejected or if the significance value for a variable is less than 0.05 , the null hypothesis will be rejected.

Step 4: Here, the calculated value 1.186 is greater than the table value and thus, null hypothesis can be rejected. 
As the significance value is 0.000 which is less than 0.05 , it ascertains that the null hypothesis can be rejected.

Step 5: Thus, it can be said that there is no gap or very little gap between expected and perceived customer service of BASIC Bank.

\section{For Pair 4:}

\section{Step 1:}

H0: There is a gap between expected customer service and perceived customer service

H1: There is no gap between expected customer service and perceived customer service

Step 2: Level of Significance is considered at 0.05 level. The table value for t-distribution under corresponding degrees of freedom is 1.9842 .

Step 3: The decision rule is, if $t_{\text {cal }}>t_{\text {cri }}$, $H 0$ will be rejected or if the significance value for a variable is less than 0.05 , the null hypothesis will be rejected.

Step 4: Here, the calculated value 1.186 is greater than the table value and thus, null hypothesis can be rejected. As the significance value is 0.004 which is less than 0.05 , it ascertains that the null hypothesis can be rejected.

Step 5: Thus, it can be said that there are very little gap between expected and perceived customer service of BASIC Bank.

\section{For Pair 5:}

\section{Step 1:}

H0: There is a gap between expected customer service and perceived customer service

H1: There is no gap between expected customer service and perceived customer service

Step 2: Level of Significance is considered at 0.05 level. The table value for t-distribution under corresponding degrees of freedom is 1.9842 .

Step 3: The decision rule is, if $t_{\text {cal }}>t_{\text {cri }}$, H0 will be rejected or if the significance value for a variable is less than 0.05 , the null hypothesis will be rejected.

Step 4: Here, the calculated value 1.186 is greater than the table value and thus, null hypothesis can be rejected. As the significance value is 0.000 which is less than 0.05 , it ascertains that the null hypothesis can be rejected.

Step 5: Thus, it can be said that there is no gap or very little gap between expected and perceived customer service of BASIC Bank.

\section{For Pair 6:}

\section{Step 1:}

H0: There is a gap between expected customer service and perceived customer service

H1: There is no gap between expected customer service and perceived customer service

Step 2: Level of Significance is considered at 0.05 level. The table value for t-distribution under corresponding degrees of freedom is 1.9842 .

Step 3: The decision rule is, if $t_{\text {cal }}>t_{\text {cri }}$, $H 0$ will be rejected or if the significance value for a variable is less than 0.05 , the null hypothesis will be rejected.

Step 4: Here, the calculated value 1.186 is greater than the table value and thus, null hypothesis can be rejected. As the significance value is 0.001 which is less than 0.05 , it ascertains that the null hypothesis can be rejected.

Step 5: Thus, it can be said that there are very little gap between expected and perceived customer service of BASIC Bank.

\section{For Pair 7:}

\section{Step 1:}

H0: There is a gap between expected customer service and perceived customer service

H1: There is no gap between expected customer service and perceived customer service

Step 2: Level of Significance is considered at 0.05 level. The table value for t-distribution under corresponding degrees of freedom is 1.9842 .

Step 3: The decision rule is, if $\mathrm{t}_{\mathrm{cal}}>\mathrm{t}_{\mathrm{cr}}, \mathrm{H} 0$ will be rejected or if the significance value for a variable is less than 
0.05 , the null hypothesis will be rejected.

Step 4: Here, the calculated value 1.186 is greater than the table value and thus, null hypothesis can be rejected. As the significance value is 0.000 which is less than 0.05 , it ascertains that the null hypothesis can be rejected.

Step 5: Thus, it can be said that there is no gap or very little gap between expected and perceived customer service of BASIC Bank.

\section{For Pair 8:}

\section{Step 1:}

H0: There is a gap between expected customer service and perceived customer service

H1: There is no gap between expected customer service and perceived customer service

Step 2: Level of Significance is considered at 0.05 level. The table value for t-distribution under corresponding degrees of freedom is 1.9842 .

Step 3: The decision rule is, if $t_{\text {cal }}>t_{\text {cri }}$, $H 0$ will be rejected or if the significance value for a variable is less than 0.05 , the null hypothesis will be rejected.

Step 4: Here, the calculated value 1.186 is greater than the table value and thus, null hypothesis can be rejected. As the significance value is 0.000 which is less than 0.05 , it ascertains that the null hypothesis can be rejected.

Step 5: Thus, it can be said that there is no gap or very little gap between expected and perceived customer service of BASIC Bank.

\section{For Pair 9:}

\section{Step 1:}

H0: There is a gap between expected customer service and perceived customer service

H1: There is no gap between expected customer service and perceived customer service

Step 2: Level of Significance is considered at 0.05 level. The table value for t-distribution under corresponding degrees of freedom is 1.9842 .

Step 3: The decision rule is, if $t_{\text {cal }}>t_{\text {cri }}$, $H 0$ will be rejected or if the significance value for a variable is less than 0.05 , the null hypothesis will be rejected.

Step 4: Here, the calculated value 1.186 is greater than the table value and thus, null hypothesis can be rejected. As the significance value is 0.000 which is less than 0.05 , it ascertains that the null hypothesis can be rejected.

Step 5: Thus, it can be said that there is no gap or very little gap between expected and perceived customer service of BASIC Bank.

\section{For Pair 10:}

\section{Step 1:}

H0: There is a gap between expected customer service and perceived customer service

H1: There is no gap between expected customer service and perceived customer service

Step 2: Level of Significance is considered at 0.05 level. The table value for t-distribution under corresponding degrees of freedom is 1.9842 .

Step 3: The decision rule is, if $t_{\text {cal }}>t_{\text {cri }}, H 0$ will be rejected or if the significance value for a variable is less than 0.05 , the null hypothesis will be rejected.

Step 4: Here, the calculated value 1.186 is greater than the table value and thus, null hypothesis can be rejected. As the significance value is 0.000 which is less than 0.05 , it ascertains that the null hypothesis can be rejected.

Step 5: Thus, it can be said that there is no gap or very little gap between expected and perceived customer service of BASIC Bank.

\section{For Pair 11:}

\section{Step 1:}

H0: There is a gap between expected customer service and perceived customer service

H1: There is no gap between expected customer service and perceived customer service

Step 2: Level of Significance is considered at 0.05 level. The table value for t-distribution under corresponding 
degrees of freedom is 1.9842 .

Step 3: The decision rule is, if $t_{\text {cal }}>t_{\text {cri }}$, $H 0$ will be rejected or if the significance value for a variable is less than 0.05 , the null hypothesis will be rejected.

Step 4: Here, the calculated value 1.186 is greater than the table value and thus, null hypothesis can be rejected. As the significance value is 0.000 which is less than 0.05 , it ascertains that the null hypothesis can be rejected.

Step 5: Thus, it can be said that there is no gap or very little gap between expected and perceived customer service of BASIC Bank.

\section{For Pair 12:}

\section{Step 1:}

H0: There is a gap between expected customer service and perceived customer service

H1: There is no gap between expected customer service and perceived customer service

Step 2: Level of Significance is considered at 0.05 level. The table value for t-distribution under corresponding degrees of freedom is 1.9842 .

Step 3: The decision rule is, if $t_{\text {cal }}>t_{\text {cri }}, H 0$ will be rejected or if the significance value for a variable is less than 0.05 , the null hypothesis will be rejected.

Step 4: Here, the calculated value 1.186 is greater than the table value and thus, null hypothesis can be rejected. As the significance value is 0.000 which is less than 0.05 , it ascertains that the null hypothesis can be rejected.

Step 5: Thus, it can be said that there is no gap or very little gap between expected and perceived customer service of BASIC Bank.

\section{For Pair 13:}

\section{Step 1:}

H0: There is a gap between expected customer service and perceived customer service

H1: There is no gap between expected customer service and perceived customer service

Step 2: Level of Significance is considered at 0.05 level. The table value for t-distribution under corresponding degrees of freedom is 1.9842 .

Step 3: The decision rule is, if $\mathrm{t}_{\text {cal }}>\mathrm{t}_{\text {cri }}, \mathrm{H} 0$ will be rejected or if the significance value for a variable is less than 0.05 , the null hypothesis will be rejected.

Step 4: Here, the calculated value 1.186 is greater than the table value and thus, null hypothesis can be rejected. As the significance value is 0.000 which is less than 0.05 , it ascertains that the null hypothesis can be rejected.

Step 5: Thus, it can be said that there is no gap or very little gap between expected and perceived customer service of BASIC Bank.

\section{For Pair 14:}

\section{Step 1:}

H0: There is a gap between expected customer service and perceived customer service

H1: There is no gap between expected customer service and perceived customer service

Step 2: Level of Significance is considered at 0.05 level. The table value for t-distribution under corresponding degrees of freedom is 1.9842 .

Step 3: The decision rule is, if $t_{\text {cal }}>t_{\text {cri }}$, $H 0$ will be rejected or if the significance value for a variable is less than 0.05 , the null hypothesis will be rejected.

Step 4: Here, the calculated value 1.186 is greater than the table value and thus, null hypothesis can be rejected. As the significance value is 0.000 which is less than 0.05 , it ascertains that the null hypothesis can be rejected.

Step 5: Thus, it can be said that there is no gap or very little gap between expected and perceived customer service of BASIC Bank.

\section{Recommendations}

From this study, we can learn that there exist some gaps in service providing process. To remove this gap, the overall organizational system should be changed and improved. Following criteria are recommended from clients' viewpoint to reduce the service gaps and increase customer satisfaction. 
- The company mission should include a focus on customers.

- Training and motivational programmers' should be introduced to improve the employee skill.

- $\quad$ The bank should take steps to minimize the operation time.

- The bank has to be more conscious of building customer relationship. To do this, the bank can consider "Customer Involvement Program."

- The bank management should ensure that all employees posses skill and quality.

- Employees have to express solidarity with the customer.

- Employees have to be aware of customer expectations.

- As this is the largest commercial bank of country, more employees have to be engaged here to serve the customers properly.

- $\quad$ Every client should be focused individually.

- There is a bureaucratic practice in this bank. This bureaucratic relationship between the management and front line personnel should be removed.

- $\quad$ More modern equipments have to be introduced here to provide better service.

- $\quad$ To provide better transaction facilities, new ATM booth should be established.

- In this bank, the employees are always in a pressure. They may be provided some recreational facilities to offer them mental satisfaction.

- $\quad$ E-banking facilities of this bank have to be more improved.

- The bank should develop own ATM or CDM system to provide service quickly and comfortably.

- The number of ATM booth should be increased

- Often the ATM booths of the bank become disabled.

- The concerned authority should remove this problem immediately.

\section{Conclusion}

BASIC Bank Limited is a state owned bank. It is committed to provide high quality financial services / products to contribute to the growth of GDP of the country through stimulating trade and commerce, accelerating the pace of industrialization, boosting up export, creating employment opportunity for the educated youth, poverty alleviation, raising standard of living of limited income group and overall sustainable socio-economic development of the country. BASIC Bank has made a strong position through its varies activities. Its number of clients, amount of deposit and investment money increases day by day. This bank already has shown impressive performance in investment. Consumer are more or less satisfied with the present services of the bank now should think to start new services and take different types of marketing strategy to get more customers in this competition market of banking. If they found gap could be removed from the process the level of satisfaction would be even greater. At last it can be said that BASIC Bank Ltd. is growing fast and its contribution in our economy is also considerable. I hope that BASIC Bank will widen its services by expanding its branch all over the country.

\section{References}

Jain, S. K., \& Gupta, G. (2004). Measuring Service Quality: SERVQUAL vs. SERVPERF Scales. Vikalpa, 29(2).

Khan, F. (2012). An Analysis of the Service Gap of Advertising Agencies in Bangladesh: An Empirical Study on Ad Agency Clients. Bangladesh Research Publications Journal, 3(4), 1171-1180.

Parasuraman, A. (2004). Assessing and improving service performance for maximum impact: insights from a two-decade-long research journey. Performance Measurement and Metrics, 5(2), $45-52$. http://dx.doi.org/10.1108/14678040410546064

Parasuraman, A. et al. (1985). A Conceptual Model of Service Quality and Its Implications for Future Research. Journal of Marketing, Fall, 41-50. http://dx.doi.org/10.2307/1251430

Parasuraman, A., Berry, L. L., \& Zeithaml, V. A. (1990). Guidelines for conducting service quality research. Marketing Research, 2(4), 34-44.

Parasuraman, A., Zeithaml, V. A., \& Berry, L. L. (1988). SERVQUAL: A multiple-Item Scale for Measuring consumer Perceptions of Service Quality. Journal of Retailing, 64(Spring), 12-40. 
Phillips, L., Chang, D., \& Buzzell, R. (1983). Product Quality, Cost Position and Business Performance: A Test of Some Key Hypotheses. Journal of Marketing, 47, 26-43. http://dx.doi.org/10.2307/1251491

Reichheld, F., \& Sasser, W. E. (1990). Zero defections: quality comes to service. Harvard Business Review, September-October, 105-116.

Schlesinger, L. A., \& Heskett, J. L. (1991). The service-driven service company. Harvard Business Review, 71-81.

Urban, W. (2011). Service quality gaps and their role in service enterprises development. Technological and Economic Development of Economy, 15(3), 631-645.

Yavas, U., Bilgin, Z., \& Shemwell, D. J. (1997). Service Quality in the Banking Sector in an Emerging Economy: A Consumer Survey. International Journal of Bank Marketing, 15(6), 217-223. http://dx.doi.org/10.1108/02652329710184442

Zeithaml, V. A., Berry, L. L., \& Parasuraman, A. (1988). Communication and Control Processes in the Delivery of Service Quality. Journal of Marketing, 52(April), 36. http://dx.doi.org/10.2307/1251263

\section{Copyrights}

Copyright for this article is retained by the author(s), with first publication rights granted to the journal.

This is an open-access article distributed under the terms and conditions of the Creative Commons Attribution license (http://creativecommons.org/licenses/by/3.0/). 